$5-1998$

\title{
Mechanical Properties of the Tendinous Equine Interosseus Muscle are Affected by in Vivo Transducer Implantation
}

\author{
M. O. Jansen \\ Ultrecht University \\ H. C. Schamhardt \\ Utrecht University
}

Antonie J. van den Bogert

Cleveland State University, a.vandenbogert@csuohio.edu

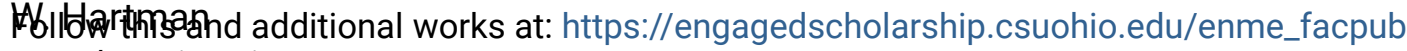

Itrecht University

Part of the Biomechanical Engineering Commons

How does access to this work benefit you? Let us know!

\section{Publisher's Statement}

NOTICE: this is the author's version of a work that was accepted for publication in Journal of Biomechanics. Changes resulting from the publishing process, such as peer review, editing, corrections, structural formatting, and other quality control mechanisms may not be reflected in this document. Changes may have been made to this work since it was submitted for publication. A definitive version was subsequently published in Journal of Biomechanics, 31, 5, (05-01-1998); 10.1016/S0021-9290(98)00023-2

\section{Original Citation}

Jansen, M. O., Schamhardt, H. C., van den Bogert, A. J., 1998, "Mechanical Properties of the Tendinous Equine Interosseus Muscle are Affected by in Vivo Transducer Implantation," Journal of Biomechanics, 31(5) pp. 485-490.

This Article is brought to you for free and open access by the Mechanical Engineering Department at EngagedScholarship@CSU. It has been accepted for inclusion in Mechanical Engineering Faculty Publications by an authorized administrator of EngagedScholarship@CSU. For more information, please contact library.es@csuohio.edu. 


\title{
Mechanical Properties of the tendinous equine interosseus muscle are affected by in vivo transducer implantation
}

\author{
M.O. Jansen ${ }^{\mathrm{a}, 1}$, H.C. Schamhardt ${ }^{\mathrm{a}, *}$, A.J. van den Bogert ${ }^{\mathrm{b}}$, W. Hartman ${ }^{\mathrm{a}}$ \\ "Equine Biomechanics Research Group, Department of Veterinary Anatomy, Faculty of Veterinary Medicine, Utrecht University, The Netherlands \\ ${ }^{\mathrm{b}}$ Department of Biomedical Engineering, Lerner Research Institute, Cleveland Clinic Foundation, Cleveland, USA
}

\section{Introduction}

The high incidence of serious injuries in the flexor tendons in the forelimb of the horse suggests that they are loaded close to their maximal capacity (Genovese and Simpson, 1989; Webbon, 1977). This was the rationale for determining in vivo strains and forces in the four tendinous structures in the equine forelimb, using implanted liquid metal strain gauges (LMSGs).

A limitation of the custom-made LMSGs used earlier (Jansen et al., 1993a; Riemersma et al., 1996) was that they lasted for no more than one day. Therefore the

\footnotetext{
* Corresponding author. Tel.: 003130 2534324; fax: 0031302516853 ; e-mail: h.c.schamhardt@POBox.uu.nl.

${ }^{1}$ Present address: Department of Anatomy and Embryology, Free University of Amsterdam, The Netherlands.
}

entire procedure, from implantation, through data collection, to post mortem calibration of tendon strain and force, had to be carried out within one day. Later the design of the LMSGs was improved, increasing their lifespan for in vivo use to 5 days. This allowed for a recovery period of 3 days after surgery and 2 days for in vivo and post mortem recordings. LMSGs were implanted in the four tendons in the forelimbs of six ponies (Fig. 1). During analysis of the data some rather unexpected findings were encountered. Compared to the former experiments, the in vivo peak strains were distinctly higher. Furthermore, the post mortem failure strains were considerably higher than those found previously (Jansen and Savelberg, 1994).

Although all four 'tendons' in the forelimb were instrumented with LMSGs in the original experiments, the present paper presents data obtained from the suspensory ligament (SL) only. Unlike the other tendons, the SL 
does not have an active muscle belly between the origin and the tendon. Furthermore, the SL is an almost completely collagenous, passive structure which crosses the metacarpophalangeal (fetlock) joint only. Therefore, the SL origo-insertional length $\left(L_{\mathrm{OI}}\right)$, and thus its OIstrain $\left(\varepsilon_{\mathrm{OI}}\right)$ is solely determined by the change in fetlock joint angle. Consequently, $\varepsilon_{\mathrm{OI}}$ of the instrumented SL could be calculated from kinematics recorded before and after LMSG implantation, which allows for a direct comparison of $\varepsilon_{\mathrm{OI}}$ and $\varepsilon_{\mathrm{LSMG}}$. In addition, tensile and failure test data were available to compare post mortem and in vivo instrumented SLs of the contra lateral limbs. This approach allows confirmation of the statement that tendon local mechanical properties changed after in vivo transducer implantation.

\section{Methods}

\subsection{Functional anatomy of the suspensory ligament}

The equine interosseous muscle is an almost completely tendinous band, and therefore is called the suspensory ligament (SL). It originates on the palmer aspect of the proximal third metacarpal bone and separates about halfway down this bone into lateral and medial branches, each containing a proximal sesamoid bone. Distally, the SL inserts on the palmar aspects of the first and second phalanges (Dyce et al., 1987). These remain aligned during the stance phase, and can thus be considered as one rigid segment.

\subsection{Recordings}

Six ponies (aged between 3.5 and $12 \mathrm{yr}$; body weight $220-275 \mathrm{~kg}$ ) were used for measurements of tendon strain, ground reaction forces (GRF) and kinematics. The ponies were walked on an $18 \mathrm{~m}$ indoor track, covered with a $6 \mathrm{~mm}$ thick rubber mat. Preceding implantation of the LMSGs, simultaneous recordings of GRF and kinematics of the left forelimb were taken at the walk and the trot, using a Kistler force plate (type 9261) and a modified CODA-3 gait analysis system (Schamhardt et al., 1992). The markers of the CODA-3 system were fixed in plastic holders, which were glued to the skin at sites indicated in Fig. 1. The holders remainded attached to the skin throughout the experiment, ensuring a constant marker positioning. An accelerometer (Brüel \& Kjaer type 4383, Nærum, Denmark) was fixed to the hoof of the left forelimb, for stride detection.

Custom made LMSGs of about $15 \mathrm{~mm}$ length were sterilised using ethylene oxide and implanted under general anaesthesia. The gauges were placed in $3 \mathrm{~cm}$ longitudinal incisions in the lateral branch of the SL (Fig. 1). The gauge ends were secured to the tendon using sutures (Vicryl $^{\mathrm{R}}$ 3-0; Ethicon GmbH, Norderstedt, Germany)

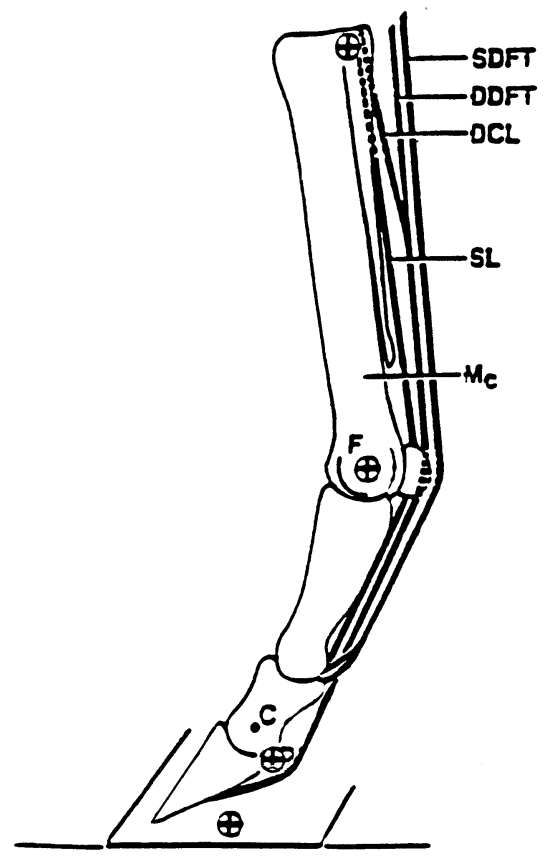

Fig. 1. Schematic drawing of the distal part of the equine forelimb. The metacarpophalangeal of fetlock joint $(\mathrm{F})$ and the distal interphalangeal or coffin joint $(\mathrm{C})$ are indicated, as well as the fetlock joint supporting tendons: the superficial and deep digital flexor tendons (SDFT and DDFT, respectively), the accessory ligament of the DDFT or distal check ligament (DCL) and the interosseous muscle or suspensory ligament (SL). Kinematic marker locations on the hoof and metacarpal segment $(\mathrm{Mc})$ are indicated by encircled crosses.

enclosing $5-15 \%$ of the tendon cross-sectional area. In this paper only results of the SL will be presented.

On the third day after surgery, simultaneous recordings of LMSG signal, GRF and kinematics were collected at the walk over at least 7 strides. On day 4, the measurements were repeated at the trot after application of local nerve blocks of the ulnar and palmar nerves. Directly following the in vivo measurements, the ponies were euthanised and the metacarpal area of the SL isolated from its origin and surrounding tissues, leaving the insertion connected to the intact digits. The relationship between tendon force and LMSG-signal was established in tensile tests according to the protocol described previously (Riemersma and Lammertink, 1988). The maximally applied force was about equal to the body weight of the pony. The cross-sectional area was determined at the narrowest site of the SL after deforming the tendon to a rectangle, and by measuring width and thickness using sliding calipers. After removal of the LMSG, the SL was loaded until failure, while recording the applied force. Next, the SL of the contralateral limb was instrumented and processed similarly, providing control values of tendon mechanical properties after acute instrumentation.

The position of joint centres of rotation, marker positions, and insertion sites of the SL with respect to limb 


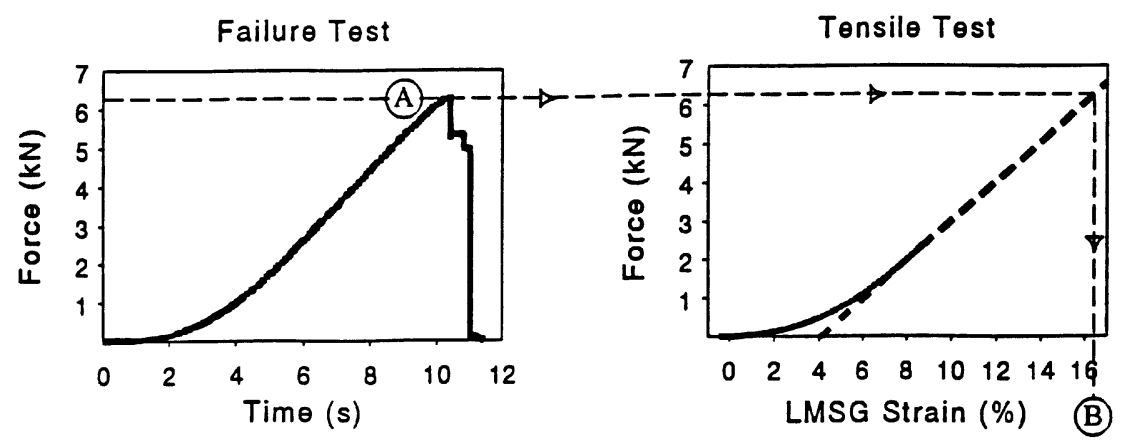

Fig. 2. The strain at total SL failure (B) was determined by linear extrapolation of the linear part of the force-strain relationship to the maximal force (A) recorded during the failure test.
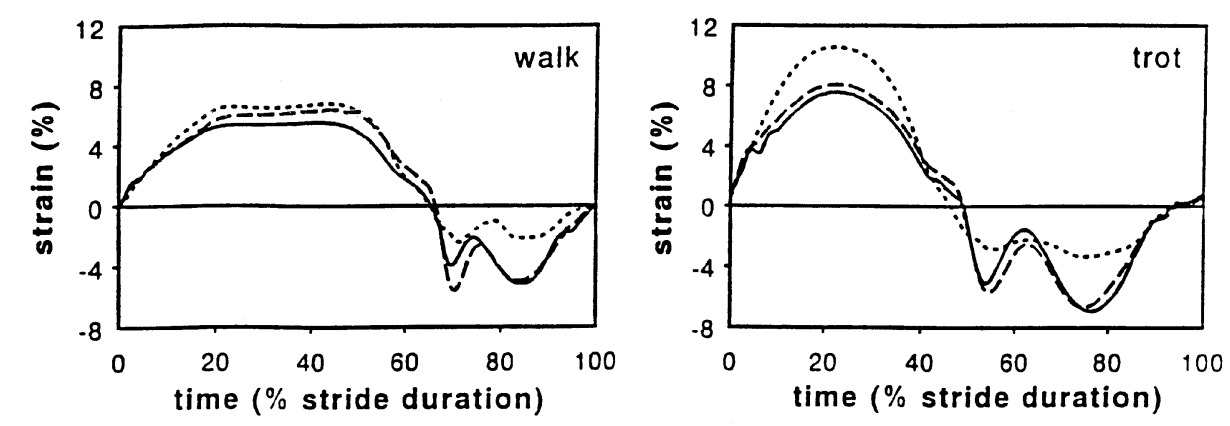

Fig. 3. Typical example of the total stride patterns of pre- and post-operative origo-insertional strain (continuous and interrupted line, respectively) and liquid- metal- strain gauge (LMSG) recorded strain (dotted line) at the walk and the trot. The onset of the stance phase is defined at $0 \%$ of the stride cycle time. The curves represent the mean of 6 or 7 strides. Differences between the curves below $0 \%$ strain are not meaningful, because negative strains merely indicate an unloaded SL.

segments were established from photographs of the frozen and sagittally sectioned limbs.

\subsection{Data analysis}

The onset and end of each stride were determined from the accelerometer signal. Signals from 5 to 8 strides were time-normalised to stride duration and ensemble averaged. The LMSG-signals were converted to strain according to:

$\varepsilon_{\mathrm{LMSG}}=100 \% *\left(\mathrm{~L}_{\mathrm{LMSG}}-\mathrm{Lo}_{\mathrm{LMSG}}\right) / \mathrm{Lo}_{\mathrm{LMSG}}$,

where $\mathrm{L}_{\mathrm{LMSG}}$ is the instantaneous LMSG length and $\mathrm{LO}_{\text {LMSG }}$ is the reference length, corresponding with the length of the tendon at zero load, which was defined to occur at initial ground contact at the walk. The origoinsertional (OI) length of the SL was also computed from the kinematic data using a 2D geometrical model consisting of two line segments, running over a pulley at the fetlock joint, as described previously (Riemersma et al., 1988). OI length was converted to strain using the same Lo definition as for the LMSG recordings.

The LMSG-signals of the post mortem tensile tests were converted to strain by defining $\mathrm{Lo}_{\text {LMSG }}$ as the LMSG length at the first detectable increase of tendon force. Tendon stress $(\sigma)$ was calculated by dividing ten- don force by cross sectional area. Tendon failure strain was estimated from the recorded failure force by linear extrapolation of the linear part of the force- $\varepsilon_{\text {LMSG }}$ relationship as recorded during the tensile test (Fig. 2).

For statistical analysis a two-tailed paired $t$-test was performed at a significance level of $p<0.05$, after confirming that the data were normally distributed.

\section{Results}

Five out of six ponies walked sound without local analgesics three days after surgery. On day 4, after application of local nerve blocks, the trot appeared normal in all ponies except pony 4 which remained moderately lame. The shapes of the total stride patterns of pre- and post-operative $\varepsilon_{\mathrm{OI}}$ and $\varepsilon_{\mathrm{LSMG}}$ at the walk and the trot were almost the same (e.g. pony 2; Fig. 3), so apparently no relevant differences in gait patterns occurred after LMSG implantation. The shapes of the $\varepsilon_{\mathrm{LSMG}}$ and $\varepsilon_{\mathrm{OI}}$ curves were similar, indicating that the locally measured $\varepsilon_{\text {LSMG }}$ reflected the strain of the entire SL. Differences in peak amplitudes between $\varepsilon_{\mathrm{LSMG}}$ and $\varepsilon_{\mathrm{OI}}$ were obvious, and irrefutably indicated differences in local and origo-insertional strain, because the recordings were made simultaneously. In this example (pony 2) $\varepsilon_{\mathrm{OI}}$ was distinctly higher than before 
surgery. At the walk this may be explained partially by a slightly higher GRF acting on the limb (Table 2). At the trot however, the post-operative GRF was lower.

SL strain data were collected during 5-8 strides, and averaged. The intra-stride variation ranged from 0.05 to $0.23 \%$ strain. Group mean OI and local LMSG peak strains at the walk and the trot of 6 ponies are listed in Table 1. Although simultaneously recorded, $\varepsilon_{\text {LSMG }}$ was $0.5 \pm 0.7 \%$ strain higher than post-operative $\varepsilon_{\mathrm{OI}}$ at the walk, and $2.2 \pm 1.1 \%$ at the trot (mean of paired differences \pm S.D.). Post-operative $\varepsilon_{\mathrm{OI}}$ was slightly, but not significantly, higher than before surgery $(0.3 \pm 0.3 \%$ strain at the walk; $0.3 \pm 0.4 \%$ strain at the trot). In pony 3 , at the walk, the post-operaive $\varepsilon_{\mathrm{OI}}$ was $2 \%$ lower, despite a $3 \%$ increase in vertical GRF (GRFz; Table 2). At the trot, the post-operative strain was $4 \%$ lower than before surgery, but this may have been due to the $2.2 \%$ decreased GRFz. In pony 4, which was moderately lame

Table 1

Peak origin-insertion strain (mean \pm S.D.) of the suspensory ligament, computed from kinematics recorded before and after Liquid Metal Strain Gauge (LMSG) implantation ( $\varepsilon_{\mathrm{OI}}$ pre and $\varepsilon_{\mathrm{OI}}$ post, respectively), and local LMSG recorded strain ( $\varepsilon_{\text {LMSG }}$ post $)$ at the walk and the trot in 6 ponies

\begin{tabular}{llll}
\hline & $\varepsilon_{\text {OI }}$ pre $(\%)$ & $\varepsilon_{\text {OI }}$ post $(\%)$ & $\varepsilon_{\text {LMSG }}$ post $(\%)$ \\
\hline Walk & $4.6 \pm 0.9^{1}$ & $4.9 \pm 1.1^{1}$ & $5.4 \pm 0.9$ \\
Trot & $6.6 \pm 1.0$ & $6.9 \pm 1.1^{2}$ & $9.1 \pm 1.3^{2}$ \\
\hline
\end{tabular}

${ }^{1}$ significant difference between pre- and post-operative origo-insertional strains.

${ }^{2}$ significant difference between post-operative origo-insertional and LMSG strains. at the trot, the pre- and post-operative strains were approximately equal, despite an $11 \%$ lower post-operative GRFz.

Additional evidence for changes in tendon mechanical properties after LMSG implantation was found comparing stress-strain $\left(\sigma-\varepsilon_{\mathrm{LSMG}}\right)$ relationships of in vivo (left) and post mortem instrumented (right) SLs (Fig. 4). Except for pony 3, in vivo instrumented SLs showed higher local strains than contralateral SLs at similar stress levels. Failure strain of left forelimb SLs was $15.4 \pm 2.1 \%$ (Table 2), which was $2.0 \pm 1.2 \%$ strain higher than that of right forelimb SLs. Failure stress of left SLs was $80.0 \pm 8.2 \mathrm{MPa}$, which was $16.5 \pm 16.6 \mathrm{MPa}$ lower than that of right SLs. There was no relationship between failure area and LMSG site.

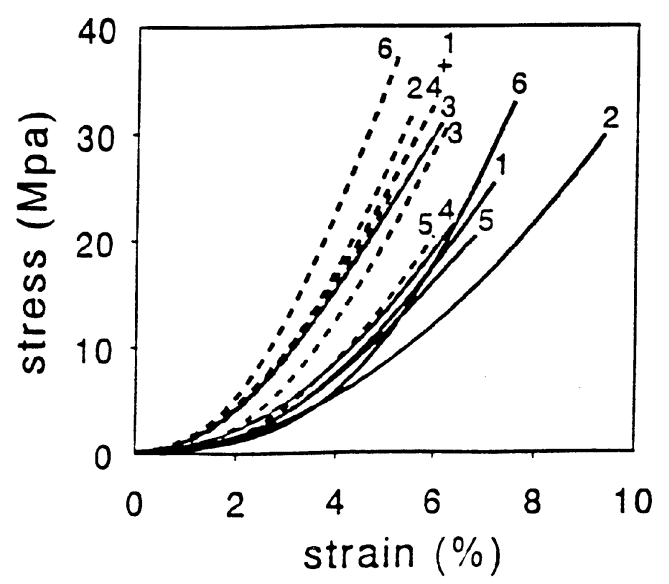

Fig. 4. The stress-strain relationship of in vivo instrumented (continuous lines) and post mortem instrumented (interrupted lines) suspensory ligaments of the forelimbs of 6 ponies. The numbers identify each pony.

Table 2

Peak (mean of 5 to 8 strides) vertical ground reaction forces $\left(\mathrm{GRFz}_{1} ; \mathrm{GRFz}_{2}\right)$, and origio-insertional strains $\left(\varepsilon_{\mathrm{OI}}\right)$ of the suspensory ligament (SL) in 6 ponies. Post operative (post) values are presented as a fraction of pre-operative (pre) data. Local peak SL strains recorded using liquid metal strain gauges $\left(\varepsilon_{\mathrm{LMSG}}\right)$ is given as fraction of the simultaneously recorded $\varepsilon_{\mathrm{OI}}$. Local strain, force and stress at total failure $\left(\varepsilon_{\text {fail }}, \mathrm{F}_{\text {fail }}\right.$ and $\sigma_{\text {fail }}$, respectively) of the $\mathrm{SL}$ of the in vivo (iv) instrumented forelimbs are given as a fraction of values from the post mortem $(\mathrm{pm})$ instrumented forelimbs

\begin{tabular}{|c|c|c|c|c|c|c|c|c|c|c|}
\hline \multirow{2}{*}{$\begin{array}{l}\text { Pony } \\
\mathrm{nr}\end{array}$} & \multicolumn{4}{|l|}{ Walk } & \multicolumn{3}{|l|}{ Trot } & \multicolumn{3}{|c|}{ Failure test } \\
\hline & $\begin{array}{l}\mathrm{GRFz}_{1} \\
\text { post/pre }\end{array}$ & $\begin{array}{l}\mathrm{GRFz}_{2} \\
\text { post/pre }\end{array}$ & $\begin{array}{l}\varepsilon_{\mathrm{OI}} \\
\text { post/pre }\end{array}$ & $\varepsilon_{\mathrm{LMSG}} / \varepsilon_{\mathrm{OI}}$ & $\begin{array}{l}\text { GRFz } \\
\text { post/pre }\end{array}$ & $\begin{array}{l}\varepsilon_{\mathrm{OI}} \\
\text { post/pre }\end{array}$ & $\varepsilon_{\mathrm{LMSG}} / \varepsilon_{\mathrm{OI}}$ & $\begin{array}{l}\varepsilon_{\text {fail }} \\
i v / p m\end{array}$ & $\begin{array}{l}\mathrm{F}_{\text {fail }} \\
i v / p m\end{array}$ & $\begin{array}{l}\sigma_{\text {fail }} \\
i v / p m\end{array}$ \\
\hline 1 & 0.943 & 0.871 & 1.05 & 1.25 & 0.974 & 1.09 & 1.56 & 1.06 & 0.74 & 0.74 \\
\hline 2 & 1.046 & 1.034 & 1.15 & 1.06 & 0.982 & 1.06 & 1.31 & 1.27 & 0.73 & 0.68 \\
\hline 3 & 1.038 & 1.033 & 0.98 & 1.24 & 0.978 & 0.96 & 1.54 & 1.15 & 1.06 & 1.07 \\
\hline 4 & 0.905 & 1.004 & 1.05 & 0.95 & 0.889 & 0.98 & 1.11 & 1.03 & 0.85 & 0.76 \\
\hline 5 & 1.005 & 0.941 & 1.08 & 1.33 & 0.988 & 1.14 & 1.34 & 1.18 & 0.97 & 0.99 \\
\hline 6 & 0.915 & 0.983 & 1.11 & 0.94 & 1.019 & 1.06 & 1.14 & 1.23 & 0.97 & 0.85 \\
\hline Mean & 0.975 & 0.978 & $1.07^{\mathrm{a}}$ & 1.13 & 0.972 & 1.05 & $1.33^{\mathrm{b}}$ & $1.15^{\mathrm{c}}$ & 0.89 & 0.85 \\
\hline S.D. & 0.062 & 0.063 & 0.06 & 0.17 & 0.043 & 0.07 & 0.19 & 0.09 & 0.13 & 0.15 \\
\hline
\end{tabular}

${ }^{a}$ significant difference between pre- and post-operative origo-insertional strains.

${ }^{\mathrm{b}}$ significant difference between post-operative origo-insertional and LMSG strains.

${ }^{\mathrm{c}}$ significant difference between strains at failure comparing in vivo and post mortem instrumented contra lateral tendons. 
In post mortem macroscopic inspection, the instrumental SL appeared normal. After removal of the LMSG, the tissue at the suture sites also appeared completely normal. Therefore, there were no indications of changes in (mechanical) properties of the collagenous material.

\section{Discussion}

Early experiments in which LMSGs were used to record equine tendon length changes were carried out in one day, because of life span limitations of these custom made transducers. After improving the manufacturing procedure, it became possible to implant the LMSG, have the animal recover from surgery, and collect data two or three days later. No evidence could be found in the literature that tendon mechanical properties changed after such a relatively short period of time (Kraus-Hansen et al., 1992; Morito et al., 1993). However, several observations in the present study suggested otherwise. The most direct evidence came from the fact that the ultimate strains determined post mortem for tendons in which LMSGs had been implanted for three days, were significantly higher than for the tendons that were instrumented post mortem (Fig. 4; Table 2). Moreover, the failure forces and stresses tended to be lower in in vivo instrumented tendons. In this comparison it was assumed that the contralateral tendons could be considered as controls, an assumption which was supported by a former study on tendons of 12 cadaver limbs (Jansen and Savelberg, 1994).

The calculated strain is sensitive to the definition of $\mathrm{Lo}_{\text {LMSG }}$, which is the momentary length of the LMSG at the initial increase in overall tendon force. Since the LMSG is connected to a fraction of the tendon fibres only, a possible error in $\mathrm{Lo}_{\text {LMSG }}$ may be expected when the fibres to which the LMSG is attached become strained earlier or later than the bulk of the tendon fibres. This may result in a random error in $\mathrm{Lo}_{\mathrm{LMSG}}$. However, $\varepsilon_{\text {LMSG }}$ appears to be systematically greater than $\varepsilon_{\mathrm{OI}}$. Therefore, the larger strain can only be explained by local changes in SL mechanical properties. After in vivo LMSG implantation neither the failure stress, nor the $\varepsilon_{\mathrm{OI}}$ before and after surgery showed marked differences, which indicated that the local changes only slightly affected the structure as a whole.

Conclusive evidence for changed local tendon mechanical properties was also found in the large difference of $2.2 \%$ strain between $\varepsilon_{\mathrm{LMSG}}$ and $\varepsilon_{\mathrm{OI}}$ at the trot. Note that these data were collected simultaneously. Strain data at the walk showed the same tendency, but the differences were smaller, probably due to the lower strain amplitude and/or the shorter time after implantation. The strain differences are in sharp contrast with earlier data, which showed almost identical local and overall strains in acute experiments (Jansen et al., 1993b). Furthermore, it was shown that equine hind limb tendons strain almost uniformly (Riemersma et al., 1985), so excessively high local strains are not to be expected. Finally, in an earlier study (Jansen et al., 1993b) the relationship between the strain in the lateral branch of the SL and the fetlock joint angle was established; SL strain increased by $0.139 \%$ per degree in fetlock angle. Applied to the present data, this relationship predicted a slightly lower SL strain, in contrast with the considerably higher observed LMSG strain.

This study provided evidence that local changes of SL mechanical properties occurred within four days following transducer implantation. There is no reason to believe that similar changes would not have occurred using other types of implantable transducers, or using the same transducers implanted in other tendons. Consequently, in vivo strain and force measurements in tendons or ligaments cannot be calibrated reliably using a post mortem or in vitro calibration only, when more than three days elapse between transducer implantation and data collection. An alternative to circumvent these problems might be to apply independent methods to establish, for example, the transducer signal in vivo that corresponds with the tendon length occurring at zero force.

\section{References}

Dyce, K.M., Sack, W.O., Wensing, C.J.G., 1987. The forelimb of the horse. In: Pedersen, D., Wonsiewicz, C. (Eds.), Textbook of Veterinary Anatomy. pp. 559-567. Saunders, Philadelphia.

Genovese, R.L., Simpson, B.S., 1989. Tendon and ligament injuries. In Jones, W.E. (Ed.), Equine Sportsmedicine. Lea \& Febiger, Philadelphia, pp. 241-248.

Jansen, M.O., Bogert, A.J. van den, Riemersma, D.J., Schamhardt, H.C, 1993a. In vivo tendon forces in the forelimb of ponies at the walk, validated by ground reaction force measurements. Acta Anatomica 146, 162-167.

Jansen, M.O., Buiten, A. van, Bogert, A.J. van den, Schamhardt, H.C., 1993b. Strain of the M. interosseous medius and its Rami extensorii in the horse, deduced from in vivo kinematics. Acta Anatomica 147, $118-124$.

Jansen, M.O., Savelberg, H.H.C.M., 1994. Stress and strain of equine tendons of the forelimb at failure. Equine Veterinary Journal Supplement 17, 57-60.

Kraus-Hansen, A.E., Fackelman, G.E., Becker, C., Williams, R.M., Pipers, F.S., 1992. Preliminary studies on the vascular anatomy of the equine superficial digital flexor tendon. Equine Veterinary Journal $24,46-51$.

Morito, T., Takai, S., Dohno, H., Okuda, Y., Hirasawa, Y., 1993. The effect of passive motion on mechanical properties of rabbit flexor tendon after denervation. In: ISB XIV ${ }^{\text {th }}$ Congress Abstracts, Paris.

Riemersma, D.J., Schamhardt H.C., 1985. In vitro mechanical properties of equine tendons in relation to cross-sectional area and collagen content. Research in Veterinary Science 39, 263-270.

Riemersma, D.J., Lammertink, J.L.M.A., 1988. Calibration of the mercury-in-Silastic strain gauge in tendon load experiments. Journal of Biomechanics 20, 469-476. 
Riemersma, D.J., Bogert, A.J. van den, Schamhardt, H.C., Hartman, W., 1988. Kinetics and kinematics of the equine hind limb: in vivo tendon strain and joint kinematics. American Journal of Veterinary Research 49, 1353-1359.

Riemersma, D.J., Bogert A.J. van den, Jansen, M.O., Schamhardt H.C., 1996. Influence of shoeing on ground reaction forces and tendon strains in the forelimbs of ponies. Equine Veterinary Journal 28, 126-132.
Schamhardt, H.C., Bogert, A.J. van den, Lammertink, J.L.M.A., Markies, H., 1992. Measurement and analysis of equine locomotion using a modified CODA-3 kinematic analysis system. In: proceedings of the 8th Meeting of the ESB. Scuola dello Sport, Rome.

Webbon, P.M., 1977. A post mortem study of equine digital flexor tendons. Equine Veterinary Journal 9, 61-67. 